\title{
REFLEXÕES SOBRE LEITURA: LER É MUITO PERIGOSO... MAS QUE PRAZER!
}

\author{
Guaraciaba Micheletti*
}

Este artigo, se assim posso nomear este texto se origina de uma palestra proferida a estudantes de Letras e de Biblioteconomia cujo título foi "Ler é muito perigoso... mas que prazer!" Assim, traço algumas reflexões sobre o ato de ler e as implicações que a leitura tem na vida das pessoas, mantendo o mesmo tom coloquial de um encontro descontraído e do diálogo que mantive com os participantes. Ao final, respondi a algumas questões que me parecem pertinentes e mesmo provocadoras.

Inicio com a afirmação de George Steiner, num ensaio que tem o instigante título de "Alfabetização Humanista" (1988, p. 29) e sempre me conduz à reflexão: Ler corretamente é correr grandes riscos. É tornar vulnerável nossa identidade, nosso autodomínio. É, sem dúvida, uma assertiva que causa perplexidade e suscita questões sem resposta. Como ler corretamente pode representar grandes riscos? Para tratar dessa questão, convido meus leitores a pensar sobre duas outras: 1 . O que se entende por leitura? 2. Para que ler?

Durante muito tempo, entendeu-se ler como uma prática de decodificação. Ou seja, estava alfabetizado aquele que escrevesse pequenos textos extremamente simples e soubesse ler as palavras que lhe fossem apresentadas. Frequentemente, bastava que a pessoa desenhasse seu próprio nome. Sabemos que isso não torna ninguém alfabetizado. Às vezes, a pessoa ia um pouco além: decifrava umas poucas palavras que lhe permitiam conhecer o destino do ônibus em que deveria entrar para chegar a um determinado lugar ou uma placa qualquer. É necessário acentuar algo conhecido: palavras isoladas podem até apresentar indícios, possibilidades significativas, mas só têm o seu real sentido quando constroem um discurso. Desse modo, ler é ir além da decodificação, envolve compreensão e, esta, o processamento das novas informações em confronto com as anteriormente assimiladas. Atualmente, o termo alfabetização vem sendo quase substituído por letramento. Apenas troca de nomes por um modismo qualquer? Em termos teóricos não, o letramento pressupõe a aquisição de uma capacidade em que entram operações bastante complexas. É necessário que os sinais gráficos sejam aprendidos, mas o letramento pressupõe considerar-se um contexto no qual os atos de ler e escrever participem de modo ativo da vida do aluno e do cidadão. Magda B. Soares, discorrendo sobre os termos alfabetização e letramento (2004) registra que o primeiro foi sofrendo alterações ao longo das últimas décadas e o segundo começou a ser utilizado no Brasil a partir dos anos 80. Salienta que antes com a alfabetização havia método e quase nenhuma teoria; com o letramento, muita teoria e nenhum método. Para ela, a alfabetização precisa ser "reinventada", pois a alfabetização

* FFLCH- Universidade São Paulo e CCHS- Universidade Cruzeiro do Sul 
não precede o letramento, na verdade "os dois processos são simultâneos" (2004, p.15). Ao mesmo tempo que a criança adquire o sistema convencional da escrita, desenvolve "habilidades de uso desse sistema em atividades de leitura e escrita, nas práticas sociais que envolvem a língua escrita”(2004, p.14)

Desse modo, ainda que termos bastante discutidos, em termos mais amplos, alargou-se o sentido da alfabetização, e letramento designa tanto as práticas de leitura como as de escrita, numa estreita e complexa relação.

Muito tem mudado nos últimos anos com a implementação dos Parâmetros Curriculares e com as Propostas de Ensino, mas, embora se reconheça o papel interativo inscrito no ato de ler e as questões históricas e sócio-culturais que estão envolvidas no processo, não raro a prática escolar as põe de lado. Voltando à primeira questão:

\begin{abstract}
"Mas, então,o que é a leitura?- A respostanãoé simples poiso ato de ler é varável, não absoluto.Em sua definiçãomodernamais ampla, a leituraé, comose sabe,"a capacidadele extrairsentidode símbolosescritosou impressos"O leitor "empregaos símbolospara orientara recuperaçãode informaçõesde sua memóriae,em seguida,cria, com essasinformaçõesuma interpretaçã mensagemdo escritor" (FISCHER2006,p.11).
\end{abstract}

Considerando o papel da memória no processo de leitura, podemos perceber como ela depende do que somos, de nossa formação, dos nossos conhecimentos anteriores com os quais se estabelece desde o primeiro impulso leitor uma interação. Quando pensamos na segunda questão: para quê?, geralmente temos as seguintes respostas complementares, embora nem sempre sejam assim reconhecidas:

- obter informações (conhecimento);

- conseguir o autoconhecimento;

- interpretar mais adequadamente o mundo que nos rodeia e com ele interagir;

- obter prazer.

Quase sempre, quando questionamos as pessoas sobre o para que se lê, qual a finalidade da leitura, temos como resposta que é para a obtenção de conhecimentos. $\mathrm{Na}$ verdade, ao ler, não estamos extraindo da leitura o conhecimento. O que obtemos da leitura são novas informações. O conhecimento decorre de todo um processo que realizamos a partir do ato de ler. A leitura traz informações que associamos a outras préexistentes, ou ao nosso conhecimento anterior, as quais sofrerão uma revisão com transformações e acréscimos.

Entretanto, raramente pensamos nisso, a informação da leitura parece esgotar-se nela mesma. É por isso que se fala em “decorar”, memorizar um conteúdo. Memorizar não é aprender. A aprendizagem nasce do diálogo entre o já conhecido e o novo.

\footnotetext{
${ }^{1}$ Fischer cita Mitchell, D.C. The process of Reading: A Cognitve Analysis of Fluent Reading and Learning to Read. Chichester e N. York, 1982.
} 
Quanto ao autoconhecimento e à interpretação de mundo, é aqui que nos tornamos vulneráveis, nossa identidade e nosso autodomínio são postos à prova. Aqui buscamos compreender ao mundo e a nós mesmos, tanto como indivíduos quanto como seres sociais. Steiner, anteriormente citado, referia-se ao texto literário, pois, segundo suas palavras:

\begin{abstract}
Atraímos a presença, a voz do livro. Permitimos que entre, ainda que não sem reservas, em nosso íntimo. Um poema magnífico, um romance clássico entram à força em nosso interior; tomam de assalto e ocupam as praças fortes de nossa consciência. Exercem sobre nossa imaginação e desejos, sobre nossas ambições e sonhos mais secretos, um domínio estranho e contundente. (p. 28-29)
\end{abstract}

Se considerarmos com Steiner que "a leitura é uma forma de atuação", qualquer texto bem lido, uma notícia que seja, pode conduzir à reflexão. É impossível ler notícias sobre a guerra que ocorreu entre os Estados Unidos e o Afeganistão, ou sobre as lutas entre palestinos e israelenses e ficar imune, sem refletir sobre os seus propósitos declarados e não declarados. Ler expressões que, à época, foram manchetes de jornal como na Folha de São Paulo - "O império ataca" ou "O império contra-ataca" - conduz a questionamentos sobre o poder econômico e político de alguns países em face do que pode ser considerado civilização e respeito aos direitos de todos os cidadãos, independentes de sua nacionalidade, crença e outros valores ${ }^{2}$. Quando abrimos o jornal e lemos uma notícia trivial sobre o domingo de um presidente e de seus ministros não deixamos de pensar nos atos e / ou situações registradas na notícia e fazer uma avaliação.

Como nos comportamos diante delas? É impossível não refletir sobre o que somos e o que fazemos aqui neste mundo. Nos dois casos, um leitor pode começar a repensar fatos políticos e, no caso das guerras ou mesmo da violência cotidiana, o leitor vai sentir a fragilidade da existência, das relações, questionar-se sobre o que é importante ou não para sua vida. O que dizer então quando um leitor lê textos literários?

E antes de tratar do quarto item a que me referi, o prazer, lembro um pouco de textos literários dos quais gosto e que me fazem concordar com a expressão de que "ler corretamente é correr grandes riscos".

A primeira escritora de que me lembrei foi Clarice Lispector. Ninguém que a leia sai da leitura como a iniciou, sejam os contos ou os outros textos, que alguns chamam de romances, outros, de novela. De qualquer maneira, o texto dela é altamente reflexivo. Um conto como "Amor" ou "O Búfalo", de Laços de Família (1998), nos quais ela desvela os mais profundos sentimentos femininos podem ilustrar essa afirmação.

No primeiro, os sentimentos de uma dona de casa quando se depara com o que para ela seria inusitado: o sorriso de um cego, que ela vê do bonde, a faz mergulhar em busca da compreensão de sua vida pessoal e de seu papel familiar. No segundo, uma

\footnotetext{
${ }^{2}$ As manchetes, citadas de memória, aludem ao filme Star Wars que trata do conflito entre o bem e o mal para tecer uma crítica ao presidente Walter W. Bush e, até mesmo, a uma considerável parcela da população.
} 
mulher desesperada procura entender o paradoxo da natureza, toda vestida de gala ("mas é primavera") e a confusão de seus sentimentos diante do amor e da vida.

Em "Amor", depois de perder o ponto onde deveria descer, Ana entra no Jardim Botânico. Ao entrar, começa a olhar as árvores e tudo ao seu redor de uma maneira inusitada. Ela olha os bichos, olha as folhas se deteriorando. Vê, observa, toda aquela paisagem de deterioração e de vida. E fica durante algum tempo. Perde até a hora de sair de lá. Depois, volta para casa pensando de uma maneira completamente diferente. Volta para os filhos, para o marido, para aquele jantar especial que ela ia preparar. Mas nada mais é igual, pois, ao retornar, executa as tarefas com certo prazer. Compartilhando o espaço familiar e observando as crianças crescerem, experimenta uma certa felicidade, ainda que não seja uma felicidade plena. Quem ler o conto não se furtará, certamente, de questionar-se sobre o que é a felicidade, o que é a rotina e o que ela representa na vida das pessoas.

Em "O Búfalo", em meio a uma natureza extremamente viva e pulsante, uma mulher vaga por um Zoológico, realizando um quase périplo, observando o "amor" dos bichos para tentar entender suas frustrações e o desamor: "Onde aprender a odiar para não morrer de amor?" (p.131). Ela declara querer odiar, mas não é capaz de fazê-lo, pois o que encontra é o amor. Ao encontrar um búfalo, sucumbe diante dele, sem compreender seus sentimentos. Ambos os textos se concluem sem respostas, respostas que o leitor buscará na sua reflexão, no seu íntimo.

Outro escritor que ilustra o perigo da leitura é Guimarães Rosa. Alguns leitores não se sentem confortáveis quando leem Grande Sertão: Veredas (1976). Não pela dificuldade de compreensão de um texto altamente elaborado que explora as possibilidades linguísticas de um idioma para prender (ou afastar) seu leitor. Mas, porque esse texto questiona o tempo todo a existência de Deus e do diabo. O enunciador / narrador / personagem expõe a sua dúvida: Deus ou diabo. Ou seja, o mote sobre o qual se assenta a narrativa nada mais é do que a existência do bem e do mal. Mas esse homem humano de quem ele nos fala tem uma força. E também nos perguntamos: o que é o homem humano? E logo nos acode o pensamento de que praticamos as nossas maldades, mas temos um lado bom. Então, a história de Riobaldo figura aquela ambiguidade que há dentro de nós. Não há o "ou bem ou mal"... Eles simplesmente existem. E quem é que nos ajuda a pensar assim? Esse homem humano, de Guimarães Rosa.

Essas leituras se constituem, sem dúvida, em experiências extremamente reveladoras... Mas não é necessário que nos prendamos à complexidade de Clarice Lispector ou de Guimarães Rosa, é possível observar a mesma experiência na leitura de textos tidos como mais simples. Um texto singelo como o poema de Cecília Meireles, "Ou isto ou aquilo":

\footnotetext{
Ou se tem chuva e não se tem sol

Ou se tem sol, não se tem chuva!

Ou se calça a luva e não se põe o anel,

Ou se põe o anel e não se calça a luva!

Quem sobe no galho não fica no chão, Quem fica no chão não sobe nos ares.
} 
É uma grande pena que eu não possa

estar ao mesmo tempo nos dois lugares!

e vivo escolhendo o dia inteiro!

escrito para criança, alegra-nos com seu ludismo no trato com a palavra e vai além. Lembro-me de uma experiência que se passou com crianças de terceira série do ensino fundamental. Foi um trabalho em que os professores apresentavam poemas aos alunos, faziam leitura silenciosa; depois, leitura em voz alta e comentários livres a propósito do texto. Por fim, era proposta uma atividade de escrita: os alunos poderiam inspirar-se no poema e produzir um pequeno texto, não havia regras quanto a essa produção. Houve uma resposta fantástica, as crianças criaram textos bem organizados. Uma delas mencionou que "ter de levantar de manhã e ir para a escola, era muito chato fazer isso". Mas se ficasse em casa e dormisse mais (...) "eu ia deixar de aprender uma porção de coisas, ia deixar de encontrar meus amiguinhos, ia deixar de brincar no recreio." Essa é a reflexão de uma criança, que deixaria de brincar no recreio se ficasse dormindo, e registrou a percepção de que fazer escolhas é algo difícil e que tem consequências. Passamos a nossa vida fazendo escolhas. E talvez nem pensemos nisso. Mas, quando lemos esse poema tão simples, podemos nos afastar das preocupações mais cotidianas e pensar na vida. E a vida é feita de escolhas, de perdas e ganhos. Não podemos ter tudo.

Essa é uma experiência como aquelas que nos levam ao que se assemelha a um processo de imersão e emersão, referência que me vêm à memória a partir da leitura de poemas de Vinicius de Moraes, especialmente pela lembrança de "O mergulhador" (p.337), no qual um homem busca encontrar-se a si mesmo no mais fundo do oceano. Talvez por isso tenha ficado pensando no fato de que ler é mergulhar. E mergulhar de cabeça, com tudo. E quando mergulhamos, o que vamos encontrar? $\mathrm{O}$ escuro, o inferior, aquilo que dificilmente poderemos apreender. Imediatamente após essa imersão ocorre uma emersão, uma saída. É como se voltássemos à flor das águas. E, quando retornamos, não somos mais os mesmos. Seremos diferentes na nossa relação conosco e com o mundo. Talvez mais tolerantes, mais integrados à natureza da qual somos parte. Meio imunes a esse mundo capitalista, globalizado, onde tudo parece ao mesmo tempo muito igual e diferente.

Mas onde está o prazer?... Acredito que o prazer esteja nessa saída envolvendo o mergulho. Depois que mergulhamos, emergimos diferentes. E esse prazer é muito mais que o prazer intelectual. É um prazer extremamente sensorial. É o calor, é o calafrio.... que experimentamos sozinhos. Sozinhos, não. Mas na comunhão com a palavra. E me parece que esse calor, esse calafrio é o que nos torna verdadeiramente leitores críticos.

Há muita discussão sobre o conceito de leitor, leitor crítico... Como é que chegaremos a esse prazer da leitura? Ou como é que podemos ajudar nossos alunos ou nossos leitores na biblioteca ou até as nossas crianças em casa a se tornarem esses leitores que sintam prazer em perder-se e encontrar-se no texto?

Se pensarmos nos textos já citados, nas narrativas de Guimarães Rosa nas quais se põe em evidência a coexistência do bem e do mal, numa expressão como "Deus e o 
Diabo, existe é o homem humano", de Grande Sertão: Veredas, o que vem a ser esse "homem humano"; ou no poema de C. Meireles que nos coloca a todos diante dos dilemas do cotidiano: "Ou isto ou aquilo: ou isto ou aquilo... / E vivo escolhendo o dia inteiro! // Mas não consegui entender ainda /Qual é o melhor: se isto ou aquilo."

Em qualquer obra ficcional, não importa o gênero, figura essa mudança que ocorre em nós quando nos deparamos com uma experiência relatada: No filme $A$ Rosa Púrpura do Cairo $^{3}$, a personagem Cecília muda o seu modo de agir depois de assistir a um filme e, ainda que, ao final, volte ao cinema em busca de uma nova "aventura", questiona seu casamento e busca sua realização pessoal.

Se formos analisar as sensações produzidas por essas leituras de diferentes tipos e gêneros de texto, com certeza, perceberemos que algumas delas não são confortáveis, ao contrário, nos irritam, nos aborrecem, num primeiro momento. É o processo de imersão e de emersão: mergulha-se num mundo misterioso e obscuro para, em seguida, emergir-se renovado.

E volta a questão: onde ficou o prazer? Ele nasce da renovação, do encontro do eu consigo mesmo, de uma certa leveza como aquela que experimenta Ana, do conto "Amor", quando sai do Jardim Botânico, depois de ter presenciado a vida na natureza da resposta ainda que precária e mutável - da satisfação da necessidade, da busca e do encontro - mais que um divertimento. Ou ainda quando nos interrogamos sobre nossas atitudes "boas" ou "más" diante do nosso semelhante e de nós mesmos e nos encontramos com a complexidade da natureza humana.

Pode ser algo extremamente sensorial, é o calor, é o calafrio, é o rubor que se experimenta sozinho - sozinho? Não, na comunhão com a palavra. É esse o leitor crítico com o qual sonhamos.

Se tivermos como ponto de partida o que se entende por leitura e leitor nos nossos dias, conceito de leitor crítico soará tautológico, ou seja, é como se alguém dissesse "subir pra cima".

Como se constrói esse tão desejado leitor? Fala-se muito que

1. os alunos não leem;

2. não há hábitos de leitura na família;

3. é impossível fazê-los ler.

\footnotetext{
${ }^{3}$ Roteiro e direção de Woody Allen, 1985. Cecília, uma garçonete que sustenta o marido bêbado e desempregado, um homem violento e grosseiro, foge da sua triste realidade assistindo a filmes. Ao assistir pela quinta vez "A Rosa Púrpura do Cairo", o heroi da fita sai da tela para declarar seu amor por ela, fato que provoca um tumulto nos outros atores do filme. Os dois passeiam pela cidade, depois o ator volta ao filme e Cecília segue sua vida, mas a compreende de um modo diferente. Há na narrativa fílmica o questionamento do real e do imaginário.
} 
Como estou dialogando com você, meu leitor, mais uma questão, na verdade, mais de uma que da primeira decorre: O professor lê? Como o professor lê?

Nem todos leem, talvez a maioria leia muito pouco, quase nada, já ouvi diversas vezes de professores mesmo os de Língua Portuguesa que não gostam de ler.

Alunos e professores vivem numa sociedade em que, embora bombardeada por informações visuais, impera a palavra escrita, nos livros e principalmente fora deles, desde instruções de como funciona um aparelho eletrônico, instruções de uma bula de remédio, contas, carnês, cartazes e tantos outros gêneros de texto escrito que povoam o cotidiano moderno. Como nos comportamos diante dessas palavras?

Talvez, bem lá no fundo, ainda pensemos que ser alfabetizado (no sentido da decodificação dos sinais) é ser leitor. Claro, nenhum educador terá coragem de afirmar, mas frequentemente nós, professores, agimos como se assim fosse.

O bom leitor não é um ser privilegiado pelo potencial genético. O bom leitor se constrói por meio de práticas específicas, por meio de uma pedagogia da leitura. Como pensar uma pedagogia da leitura? Se considerarmos num plano de leitura e durante o seu desenvolvimento, os tópicos como os que se seguem, há grandes possibilidades da obtenção de melhores resultados:

1. refletir / questionar-se sobre o papel da leitura nas aulas de Língua Portuguesa e nas outras aulas;

2. traçar objetivos claros;

3. ter presente que o mundo e a leitura são plurais, exigindo um olhar mais amplo;

4. evitar situações estereotipadas de leitura (elaboração de fichas, resposta a questionários - não se preconiza a total abolição, mas, de acordo com os objetivos, observar dosagem e qualidade);

5. incentivar a opinião pessoal: gostei / não gostei, sempre alicerçada em argumentos;

6. procurar investigar com o aluno marcas de linguagem que possam facilitar a compreensão, verificando a possibilidade de "descobrir" o ponto de vista do autor do texto (simulações, disfarces, ambiguidades,);

7. trazer para a leitura em sala de aula textos dos mais variados gêneros e investigar com os alunos as peculiaridades das diferentes linguagens desconstruindo e reconstruindo textos.

Por fim, é preciso que o professor seja um leitor. Se o professor ou o responsável pela formação do leitor não for capaz de perder-se e encontrar-se, perder-se e encontrarse, perder-se e encontrar-se, múltiplas vezes, continuamente, é pouco provável que ele consiga transmitir esse perigo, esse prazer! 


\section{Diálogo que se seguiu à palestra}

Transcrevo, a seguir, algumas das questões que me foram formuladas pelos participantes. A intenção inicial era ter registrado toda a palestra, o que não foi possível devido a problemas técnicos da gravação. O que registro, por sugestão de colegas, são questões que despertaram maior interesse.

P: Existem leituras que podem prejudicar o aluno? E que sejam perigosas nesse sentido?

G: Penso que se indicarmos uma leitura para a qual o grupo não esteja preparado, correse esse risco. As leituras devem ser selecionadas de acordo com o nível de desenvolvimento dos alunos. Isso não quer dizer que cada aluno pode escolher um livro para ler, prática que tem sido bastante preconizada. Cada aluno vai à biblioteca ou à caixa de leitura, escolhe, lê; e, depois, não há nenhuma avaliação. Ou, quando há, são propostas questões tão genéricas e inespecíficas. Não acredito que uma pedagogia de leitura possa ser assim construída, embora muitos professores acreditem nisso. Desse modo, não se desperta curiosidade no leitor nem questões que lhe ocupem o pensamento por algum tempo. Talvez seja uma questão pessoal, mas não acredito nisso. Penso que devemos aprender a ser leitores. E a leitura de uma obra poderá nos proporcionar prazer ou desprazer. Preciso ter a liberdade de dizer que não gostei do livro, mas devo lê-lo. É necessário aprender a ler aquilo de que não se gosta também. Até para que se explique por que não se gosta.

Entretanto não vou pedir a um aluno de Ensino Fundamental que leia Guimarães Rosa, especialmente Grande Sertão: Veredas. Mas posso indicar a leitura de um conto de Machado de Assis. Vocês já imaginaram um jovenzinho de 14 ou 15 anos lendo "Uns braços", com aquele rapaz cobiçando a mulher do outro pelos braços? Hoje ninguém mais cobiçaria os braços, porque os braços eram extremamente atraentes. Que diálogo interessante que o professor poderia estabelecer com seus alunos sobre épocas, costumes, moralidade... Penso que começaria a ganhar um leitor a partir daí. E um leitor para Machado de Assis. E esse leitor poderia depois ir buscar outras obras.

Talvez surja um questionamento: mas, que Machado indicar aos alunos se ele trata de questões psicológicas tão delicadas? As pessoas, mesmo as crianças, têm conflitos e necessidade de extravasá-los. E a ficção proporciona essa oportunidade. É só nos perguntarmos por que as novelas e programas como Big Brother Brasil, da TV Globo, possuem tanta audiência e envolvem os telespectadores. Assim, desde que se considere o nível de desenvolvimento dos alunos, os textos não farão nenhum mal às pessoas ditas normais. As pessoas que não têm problemas psicológicos mais graves são capazes de mergulhar nas ondas da ficção ou do poema e sair do mergulho, voltar à tona mais íntegras que ao início da leitura. Penso que, em casos diferenciados, de patologias, a pessoa possa perder o controle de suas emoções. Mas o normal (e é bom lembrar que 
ninguém é muito normal), aquele que o senso comum chama de normal é capaz de mergulhar e de sair do mergulho.

O perigo não está aí. Talvez o maior perigo sejam as questões insípidas ("chatas") que formulamos sobre os livros indicados. Já vi crianças que gostavam de ler e começaram a detestar, porque o professor fica perguntando detalhes do livro. Detalhes que, na maioria das vezes, nada significam para a criança. Depois, ela não quer ler o outro livro. Por que uma criança que é leitora e que tem um ambiente de leitura dentro de casa, sempre foi leitora, amou ganhar livros de presente, num determinado momento não quer mais ler? Porque ficou sem "graça". Porque ela não é capaz de se encontrar lá no que está lendo, embora os livros escolhidos tenham sido livros até interessantes, infanto-juvenis.

Um dos trabalhos que meu grupo de pesquisa da década de 90 fez foi selecionar livros que considerávamos estereotipados (e mostrávamos por que estereotipados) e tentar mostrar que um livro, ainda que não tão bem realizado, poderia ser bem trabalhado na sala de aula. O professor poderia comentar com seus alunos os problemas encontrados, fazendo observações, propondo questões. "Olha o que tem aqui. Estranho, não? Poderia ser como? Poderia ser assim, diferente." E no momento em que ele começa a descobrir traços desse livro, com o qual não se identifica, vai compará-lo a outros e, possivelmente, buscar novos textos sobre o assunto. Isso é despertar a curiosidade, mesmo com um texto ruim.

Uma situação bastante comum: "Todo mundo na escola mandou ler esse livro. Eu não gosto, acho chato. Acho que não é bom, mas sou jovem e os outros professores são efetivos, por isso tenho que mandar ler o mesmo livro que eles indicaram."

Que fazer? O melhor é solicitar que os alunos leiam, depois fazer um trabalho diferenciado com o livro. Talvez seja bom ser tanto "anarquista" em meio aos que seguirão o roteiro e analisar o livro, identificando os seus pontos fracos. Pode-se explicar que seria melhor se o assunto tivesse sido desenvolvido de outra maneira. De certo modo, o aluno se sentirá respeitado, o professor terá ganhado a sua confiança. Possivelmente lerá outro livro que o professor solicitar. Às vezes, é necessário que o professor seja meio maroto no modo de apresentar o texto que será lido, faz parte da sedução e da conquista do aluno, mas é preciso ter consciência de nossas atitudes.

Devo ressaltar que, para isso, faz-se necessário que o professor tenha princípios éticos e morais sólidos. E como se dissesse para si mesmo: Eu sei que estou manipulando, mas meu objetivo é bom. Quero que ele leia. Depois, ele lerá como quiser. Por exemplo, se comento uma fala do presidente Lula, como aquelas que ele costuma fazer de improviso, devo considerar que trato do discurso de uma figura controversa. Assim, as opiniões, em torno de sua figura, serão muito díspares. E todos têm direito à sua opinião. É necessário, entretanto, que cada um saiba argumentar por que o prefere ou não, e que não chegue a um segundo ou terceiro ano de Letras dizendo: "Professora, vou votar no Lula, mas alguém me disse que o Lula não tem diploma e a Marta exige diploma para não sei que cargo".

\footnotetext{
${ }^{4}$ Lembrando que, à época, desse questionamento, Lula era candidato à presidência e Marta Suplicy, prefeita de São Paulo. Um dos argumentos de alguns eleitores que não votariam em Lula era de que ele não tinha formação suficiente para o cargo. $\mathrm{O}$ aluno tinha uma espécie de intuição de que, se uma petista
} 
O que poderia responder para esse aluno? Ora, não sou eu que tenho que dizer. É quem fez a opção que deve defendê-la. O aluno precisa aprender a dizer. Então, é possível ensinar-lhe que, por exemplo, o uso de "mas" aponta algo contraditório. E, por meio de um jogo de prós e contras, certamente ele aprenderá a argumentar em favor da escolha que fez ou deixou de fazer.

É isso que devemos ensinar, penso. Agora, não nos cabe dizer: "você está certo", "você está errado". Nós temos que ensiná-lo a argumentar. Por isso é que ele pode gostar ou não daquilo de que nós gostamos. Penso que temos o dever de dar-nos a nós (professores) e a eles (alunos) o direito de gostar ou não e de expressar nossas opiniões.

P: Com relação à leitura, o primeiro impacto seria esse de mostrar para a pessoa um livro, um conto, o que seja, para ela começar a ler. Mas num segundo momento, há a questão de dar um pouco de autonomia para ela decidir o que é melhor ou não... O que você acha de dar essa autonomia num segundo momento?

G: Você está colocando duas questões. A primeira refere-se ao começo de um jogo. Se o resultado desse jogo será favorável, se ele se tornará leitor ou não, dependerá muito de nós. Eu jogo com esse gosto inicial, com essa necessidade que ele tem e, depois desse jogar com a necessidade primeira, procuro criar novas necessidades.

A Educação é cheia de altos e baixos. Tenho muitos anos de sala de aula, já vivi vários momentos, como estudante e como professora. Já ouvi afirmações como: "olha, não pode corrigir mais nada, comunicou tá comunicado". Foi terrível. "Olha, não pode mais pôr autor consagrado, texto do século anterior" - nós estávamos no século XX, então não se poderia mais colocar texto de autor do século XIX no livro didático. E no livro só ficavam textos de autores modernos, contemporâneos. Havia uma perda muito grande nisso. A mescla é fundamental para o desenvolvimento linguístico e sóciocultural do aluno. Se eu indicar para leitura um conto de Machado de Assis, quando começar o ensino médio, o aluno já terá tido um primeiro contato com um dos maiores romancistas de Língua Portuguesa. É, no mínimo, um pouco de cultura geral.

É possível selecionar textos a partir de um tema, por exemplo, juntar a uma cantiga de amigo, o poema "Leito de folhas verdes", de Gonçalves Dias, e "As penélopes urbanas não têm ajuda dos deuses", de um poeta contemporâneo do Nordeste, Alberto da Cunha Melo. Isso poderia ser feito no Ensino Médio para mostrar que, neles, há um mesmo sentimento de abandono expresso por eu lírico feminino, mas a linguagem vai mudando através dos tempos. Então, os temas são universais? São. O que faz mudar alguma coisa? A linguagem do nosso tempo.

Assim, com textos literários de diferentes épocas pode-se questionar os alunos sobre os hábitos linguísticos com questões extremamente simples como: "Olhem a linguagem do fulano". "Essa linguagem seria possível no período realista, século XIX? Essa linguagem seria possível na época do Mário de Andrade? Por que ele está falando isso desse jeito? Penso que se possa ensinar os períodos literários, partindo dos

exigia diploma universitário para um cargo "menor", havia uma certa contradição e ele não sabia como validar sua preferência. 
sentimentos que todas as pessoas têm, que a humanidade sempre teve, e mostrar as diferenças entre as épocas. O professor estará cumprindo o programa que lhe cabe e os alunos, aprendendo língua, literatura, história.

Há no mercado uma imensa quantidade de livros de auto-ajuda e que são muito lidos. Em certas situações, poder-se-ia ler um desses livros e analisá-lo na sala de aula. E o ponto inicial de reflexão poderia ser o por quê eles prendem a atenção das pessoas.

P: Nesses cursos preparatórios para professores, existe alguma disciplina que indique o livro correto para o aluno, dependendo da série etc? Falo isso porque adoro ler, mas aprendi a ler com meu pai. Comecei a ler com oito anos Jorge Amado. Eu tinha a coleção do José de Alencar, e lia a coleção, mas com oito, nove anos de idade eu já entendia. Quando passei para a sétima série, tinha uma professora maravilhosa de português. E ela nos deu Para gostar de ler, aquela série de crônicas. E amei. Eu achava apropriado para minha idade. E a partir daí passei a entender mais José de Alencar, Machado de Assis...

G: Penso que não exista uma receita perfeita. Já há vários livros que discutem questões de leitura na escola. Há um livrinho (no sentido carinhoso da palavra), já publicado há vários anos, que traz uns textos que me parecem ainda atuais. Num deles, encontramos uma espécie de catálogo, não sei se é bem o termo, de livros com determinadas características que são mais interessantes para certas faixas etárias. É Leitura em crise na escola, da Mercado Aberto, organizado por Regina Zilbermann. É uma coletânea de textos que pode colaborar nesse sentido. Por outro lado, o que tenho observado - há até um artigo ${ }^{5}$ em que discuto um pouco essa questão: se existe uma estética específica da literatura infanto-juvenil. Não acredito que haja. Para mim, os mesmos valores que num texto atraem os adultos podem despertar o interesse das crianças de hoje. A linguagem, entretanto, não será exatamente a mesma da literatura para adultos.

Por exemplo: uma narrativa que rompa expectativas pode trazer, para criança, a realidade, sem ser livro realista. O importante é que o vocabulário seja acessível ao aluno. Porque se não for acessível, ele não vai parar para olhar no dicionário e resolver sua dúvida, mas o que se poderia chamar traços da literatura atual despertam o interesse na literatura infantil e juvenil. Uma narrativa como Estrelas Tortas, de Walcyr Carrasco $^{6}$, em que se discute a questão da deficiência ou um poeminha infantil como Dona Pulga ${ }^{7}$, em que se põe em foco o ser diferente, pois a pulga não gosta de pular, é "bonachona, preguiçosa" e é "despejada" pelo "cachorrinho".

P: Você acha que se deve indicar a leitura dos autores clássicos?

\footnotetext{
${ }^{5}$ Revista da Teresa Martin (1990: 9 / 11).

${ }^{6}$ Edit. Moderna, 1997.

${ }^{7}$ Wania Amarante, Cobras e Lagartos, B.H.: Miguilin, 1983
} 
G: Penso que o bom é mesclar, indicar tanto autores consagrados pela literatura dita adulta e livros escritos para um público infantil e / ou juvenil. Não se pode indicar um livro, do ponto de vista linguístico, muito difícil para o aluno. Mas, "Fita verde no cabelo", de Guimarães Rosa, a meninada pode ler. Há um texto que fala do aniversário de uma avó, da Clarice Lispector, "O aniversário", é um clássico. Pode ser lido. É mais próximo de nós. Machado tem histórias fantásticas, que são curtíssimas: "Missa do galo", por exemplo. A questão do "Peru de Natal”, de Mário de Andrade, a melhor parte do peru, para quem ia? A discussão na mesa, de quem ficaria com o melhor pedaço do peru é algo acessível aos alunos, mesmo que haja uma ou outra palavra que eles não entendam. Penso que se deva mesclar ou alternar autores da literatura "oficial" a outros ditos autores de obras infantis e / ou juvenis e, mesmo, todos os gêneros, literários ou não.

Comentário de uma participante a respeito de um texto que ela leu: Título: "O pai analfabeto consciente". O autor explica que o pai era analfabeto não por não saber ler, mas por saber e não ler. O pai trazia vários livros e revistas para o filho de oito, nove anos. Então ele os colocava na sala. O filho ficava ali lendo e o pai sentado assistindo televisão. E o menino perguntava: "Ô pai, você sabe a quantos quilômetros o Sol está da Terra?". E o pai respondia: "Não sei não." E o filho perguntava: "Ô pai, você sabe por que existem as estações do ano?" "Não sei não." "Ô pai, você sabe como funcionam as ondas do mar?" "Não sei não." E então o filho disse para o pai: "Ô pai, como eu sou chato, você querendo assistir aí seu programa e eu fico fazendo essas perguntas." E o pai: "Não, filho, você tem que perguntar mesmo, se você não perguntar você nunca vai aprender." Isso se relaciona com o que a Guaraciaba falou - do professor que quer que o aluno leia, mas não lê, ou da família que quer que o filho leia, mas não lê.

P: Mas o governo não quer justamente isso: que o povo não pense, para governar mais fácil?

G: Pois é, mas qual é o nosso papel? Não é compreender o sistema e, se necessário, enfrentá-lo em busca de uma sociedade mais justa? Nas sociedades ditas democráticas, a principal arma do cidadão é o voto. Só escolheremos representantes e governos mais adequados, se tivermos conhecimentos suficientes que nos conduzam à análise da situação do país, de seu povo e daqueles que desejam o poder. Penso que o papel do professor consciente é despertar no educando o gosto pelo conhecimento e o hábito da reflexão. É uma forma de enfrentar o sistema pela palavra, de modo pacífico, contínuo e consistente.

E concluo com essa resposta que é mais uma reflexão em voz alta.

\section{Referências bibliográficas e obras inspiradoras}


FISCHER, S.R. História da Leitura. São Paulo: UNESP, 2006.

ISER, W. O ato da leitura (trad. Kretschmer, J.) v. 1 e 2. São Paulo: Editora 34, $1996,1999$.

LISPECTOR, C. Laços de Família. Rio de Janeiro: Rocco, 1998.

MEIRELES, C. Obra Poética. Rio de Janeiro: Nova Aguilar, 1977.

MORAES, V. Poesia Completa e Prosa. Rio de Janeiro: Nova Aguilar, 1980.

ROSA, J. G. Grande Sertão: Veredas. 10ed. Rio de Janeiro: José Olympio,1986.

SILVA, E.T. da. Elementos de pedagogia da leitura. São Paulo: Martins Fontes, 1998.

SOARES, M. Letramento e alfabetização: as muitas facetas. In Revista Brasileira de Educação, Jan/Fev/Mar/Abr 2004 n.25.

STEINER, G. Linguagem e silêncio. (trad. Stuart, G. e Rajabally, F.) São Paulo: Cia das Letras, 1988. 